\title{
Cocaine self-administration in rats lacking a functional trpc4
}

\section{gene [version 1; peer review: 2 approved]

\author{
Kristin C Rasmus, Casey E O'Neill, Ryan K Bachtell, Donald C Cooper
}

Center for Neuroscience, Institute of Behavioral Genetics and Department of Psychology and Neuroscience, University of Colorado, Boulder, Boulder, CO, 80309, USA

\section{V1 First published: $17 \mathrm{Apr} 2013, \mathbf{2 : 1 1 0}$ \\ https://doi.org/10.12688/f1000research.2-110.v1}

Latest published: $17 \mathrm{Apr}$ 2013, 2:110

https://doi.org/10.12688/f1000research.2-110.v1

\section{Abstract}

The canonical transient receptor potential (TRPC) family of $\mathrm{Ca}^{2+}$ permeable, non-selective cation channels is abundantly expressed throughout the brain, and plays a pivotal role in modulating cellular excitability. Unlike other TRPC channels, TRPC4 subtype expression in the adult rodent brain is restricted to a network of structures that receive dopaminergic innervation, suggesting an association with motivation- and reward-related behaviors. We hypothesized that these channels may play a critical role in dopamine-dependent drugseeking behaviors. Here, we gathered data testing trpc4 knockout (KO) rats and wild-type (WT) littermates in the acquisition of a natural sucrose reward (10 days), and cocaine self-administration (13 days) at $0.5 \mathrm{mg} / \mathrm{kg} /$ infusion. Rats lacking the trpc4 gene (trpc4-KO) learned to lever press for sucrose to a similar degree as their WT controls. However, when they were switched to cocaine, the trpc4-KO rats had substantially reduced cocaine-paired lever pressing compared to WT controls. No obvious group differences in inactive lever pressing were observed, for any time, during cocaine self-administration.

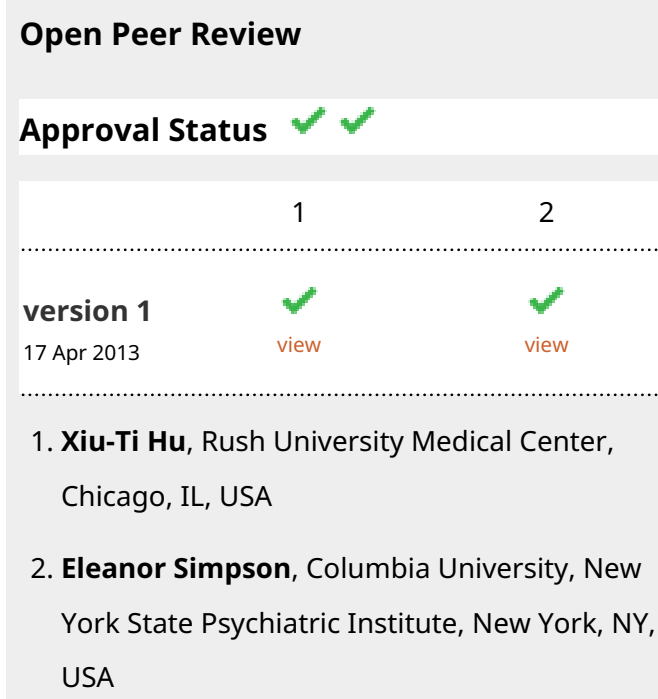

Any reports and responses or comments on the article can be found at the end of the article.

Corresponding author: Donald C Cooper (D.Cooper@colorado.edu)

Competing interests: No relevant competing interests were disclosed.

Grant information: This work was supported by National Institute on Drug Abuse (NIDA) grant R01 DA24040 (DCC). The funders had no role in study design, data collection and analysis, decision to publish, or preparation of the manuscript.

Copyright: $\odot 2013$ Rasmus KC et al. This is an open access article distributed under the terms of the Creative Commons Attribution License, which permits unrestricted use, distribution, and reproduction in any medium, provided the original work is properly cited. Data associated with the article are available under the terms of the Creative Commons Zero "No rights reserved" data waiver (CC0 1.0 Public domain dedication).

How to cite this article: Rasmus KC, O'Neill CE, Bachtell RK and Cooper DC. Cocaine self-administration in rats lacking a functional trpc4 gene [version 1; peer review: 2 approved] F1000Research 2013, 2:110 https://doi.org/10.12688/f1000research.2-110.v1 First published: 17 Apr 2013, 2:110 https://doi.org/10.12688/f1000research.2-110.v1 


\section{Introduction}

Canonical transient receptor potential (TRPC) channels are a group of non-selective cation channels that have recently gained more attention due to their involvement in neuronal excitability ${ }^{1}$. This family of channels consists of 7 members (TRPC1-7) that can be turned on in response to the activation of the $\mathrm{Gq}$ alpha subunit of G-protein-coupled receptors ${ }^{2}$. Stimulation of $\mathrm{Gq}$ alpha proteincoupled receptors activates phospholipase C Beta (PLC $\beta$ ) producing elevations in inositol triphosphate $\left(\mathrm{IP}_{3}\right)$ and intracellular $\mathrm{Ca}^{2+3}$. TRPC channels contain three calmodulin sites and an $\mathrm{IP}_{3}$ site on the C-terminus of each subunit ${ }^{4,5}$. Thus, intracellular signaling resulting from $\mathrm{Gq}$ alpha protein-coupled receptors can enhance the activity of TRPC channels ${ }^{2}$. These unique properties allow these channels to play a pivotal role in responding to intracellular $\mathrm{Ca}^{2+}$ signaling, thereby affecting neuronal excitability. The TRPC4 channel is one of the two most abundant TRPC channel subtypes found in the adult mammalian brain ${ }^{6}$. We have shown that TRPC4 channels are highly expressed in corticolimbic regions including the lateral septum, hippocampus, prefrontal cortex (PFC), and the amygdala ${ }^{6}$. The expression pattern of the TRPC4 channels within brain reward areas along with its ability to regulate neuronal excitability raised the interesting possibility that TRPC4 channels are important for motivated behaviors and may play a role in drug reinforcement. In the present study, we explored cocaine self-administration in trpc4 KO rats and their WT littermates to test the hypothesis that TRPC4 channels play a role in natural (sucrose) and drug (cocaine) rewardrelated behaviors.

\section{Materials and methods \\ Animals}

All experiments were conducted in accordance with guidelines of the 'Institutional Animal Care and Use Committees' at the University of Colorado at Boulder. Eight-week-old (250-300 grams) male trpc4-KO rats and their wild-type Fischer 344 littermates (Transposagen, Lexington, KY, USA) in these studies were housed separately. The trpc4-KO rats were generated using the Sleeping Beauty transposon system ${ }^{6}$. We have previously reported some phenotypic characteristics of trpc4-KO rats that indicate a reduction in social interaction and normal learning on simple and complex tasks ${ }^{7-9}$. In the sucrose self-administration studies, nine trpc4-KO, nine WT and 7 heterozygote rats were used, while 7 animals from each strain were used in all cocaine self-administration experiments.

\section{Animal genotyping and PCR}

Three polymerase chain reaction (PCR) primers were designed and used as 20-24 oligonucleotide sequences (Eurofins MWG Operon, Ebersberg, Germany) to genotype rats. Reactions were carried out using Choice-Taq Blue DNA polymerase (Denville Scientific Inc., Metuchen, NJ, USA) in a Techne Touchgene thermal cycler (Techne, Minneapolis, MN, USA). Ethidium bromide-stained 1.5\% agarose gels (Thermo Fisher Scientific Inc., Pittsburgh, PA, USA) were photographed with a Kodak Gel Logic 200 UV transilluminator imager (Carestream Health Inc., Rochester, NY, USA) using a $100 \mathrm{bp}$ DNA ladder in the first lane of the gel as reference (New England BioLabs, Ipswich, MA, USA).

\section{Sucrose self-administration}

All self-administration procedures were performed in operant conditioning chambers (Med-Associates, St. Albans, VT, USA) equipped with two response levers, a sucrose hopper, and an infusion pump system. Animals were food-deprived to $85 \%$ free feeding weight and trained to lever-press for sucrose pellets on a fixed ratio 1 (FR1) reinforcement schedule for 5 days/week. A discriminative cue light stimulus was illuminated above the lever paired with sucrose delivery. A correct lever response resulted in the delivery of a sucrose pellet ( $45 \mathrm{mg}$ ). With the termination of the cue light and a 20 second time out period (TO 20s), responding produced no consequence. Inactive lever responses produced no consequence throughout the session. The session was complete when the animal had administered 50 sucrose pellets and the latency (in minutes) to acquire 50 pellets was recorded as the dependent variable. Failure to reach criteria (50 pellets) within 120 minutes resulted in termination of the session. Animals completed 10 sucrose self-administration sessions, which was sufficient to establish stable baseline sucrose responding in all groups.

\section{Surgery}

Following sucrose self-administration, rats were given ad libitum food. After 24-48 hours of free feeding, catheters were implanted into the jugular vein under halothane anesthesia (1-2.5\%). During recovery, catheters were flushed daily with $0.1 \mathrm{ml}$ of $0.9 \%$ heparinized saline to maintain patency. Rats were allowed 4-7 days to recover in their home cage before experimental procedures began.

\section{Cocaine self-administration procedure}

Following at least 4-7 days recovery from surgery, animals were trained to self-administer intravenous cocaine $(0.5 \mathrm{mg} / \mathrm{kg} / 100 \mu \mathrm{l}$ injection $)$ on an FR1 schedule in daily 2-hour sessions for 5 days/week. Cocaine injections were delivered over 5 seconds and were concurrent with the illumination of a cue light above the active lever. Drug and cue delivery were followed by a 15 second time out period, where the house light remained off and responding produced no consequence. Inactive lever responses produced no consequence throughout testing. No differences were observed between groups on the inactive lever (see data set).

\section{Catheter verification}

Catheter patency was tested at the completion of the experiment to ensure that differences in self-administration were not due to catheter failure. Fatal Plus cocktail $(390 \mathrm{mg} / \mathrm{ml}$ pentobarbital sodium, $0.01 \mathrm{mg} / \mathrm{ml}$ propylene glycol, $0.29 \mathrm{mg} / \mathrm{ml}$ ethyl alcohol, $0.2 \mathrm{mg} / \mathrm{ml}$ benzyl alcohol) was administered through the animal's catheter at $0.2 \mathrm{ml} / \mathrm{kg}$. Catheter patency was confirmed if the animal responded immediately (within 1 second) with muscle atonia and lethality following Fatal Plus administration. Animals with faulty catheters $(n=4)$ were excluded from these studies (see data set).

\section{Drugs}

Fatal Plus was obtained from Vortech Pharmaceuticals, LTD (Dearborn, MI, USA). Cocaine hydrochloride was obtained from Sigma-Aldrich (St. Louis, MO, USA). Cocaine was dissolved in sterile-filtered physiological saline $(0.9 \%)$. 


\section{Results}

Generation of trpc4 knock-out rats

The Sleeping Beauty (SB) gene-trap transposon method was used to create the trpc4-KO animals ${ }^{7}$. The SB method uses cut-and-paste transposable elements to generate heritable loss-of-function mutations. Figure 1A shows the location of the trpc4 gene on the rat genome and where the transposon was inserted. By inserting the SB transposon into the first intron of the trpc 4 gene, the full-length protein product can be deleted. Using primers for the trpc4-KO and WT alleles, we were able to confirm the deletion using PCR and gel electrophoresis (Figure 1B).

\section{Sucrose self-administration}

As shown in Figure 2A, both the trpc4-KO rats and their WT littermates acquired 50 sucrose pellets at similar levels during the first 3 days and last 3 days of sucrose training. By day 7, all groups reached stable baseline, responding averaged between 16 and 26 seconds to acquire 50 pellets. Thus, it appears that trpc4-KOs do not differ in their ability to learn to self-administer a natural reward, sucrose, on a FR-1 schedule (see data set). The submitted data set contains responding on the active and inactive levers and the number of sucrose pellets for all three treatment groups across ten days of sucrose training.

A

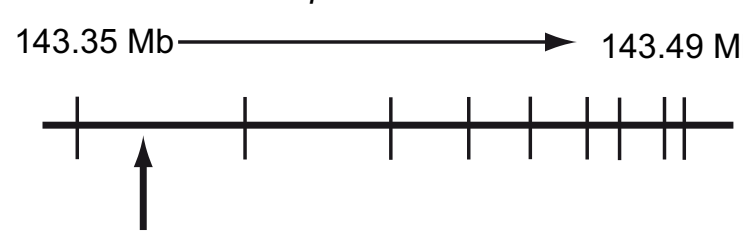

Transposon inserted into 1st intron of trcp4 gene.

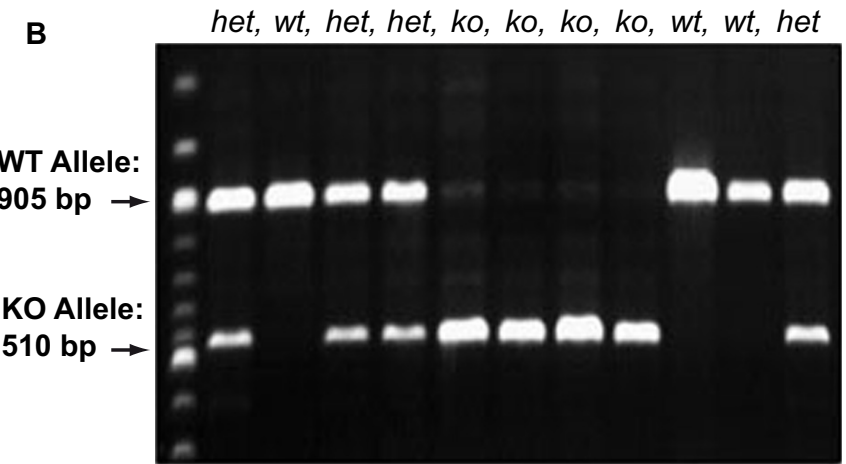

Figure 1. Generation of the trpc4 knock-out (KO). A. Schema of the trpc4 gene in the rat genome and the Sleeping Beauty (SB) gene knock-out system. The trpc4 gene is located on chromosome 2 of the rat genome, between $143.35 \mathrm{Mb}$ and $143.49 \mathrm{Mb}$. The SB transposon was inserted into the first intron of trpc4, therefore creating a complete knock-out of the coding sequence. B. Ethidium bromide-stained agarose gel visualizing the $905 \mathrm{bp}$ marker for the wild-type allele and the $510 \mathrm{bp}$ marker for the trpc4 $\mathrm{KO}$ allele. To genotype the animals, $1.5 \%$ agarose gel electrophoresis was used.
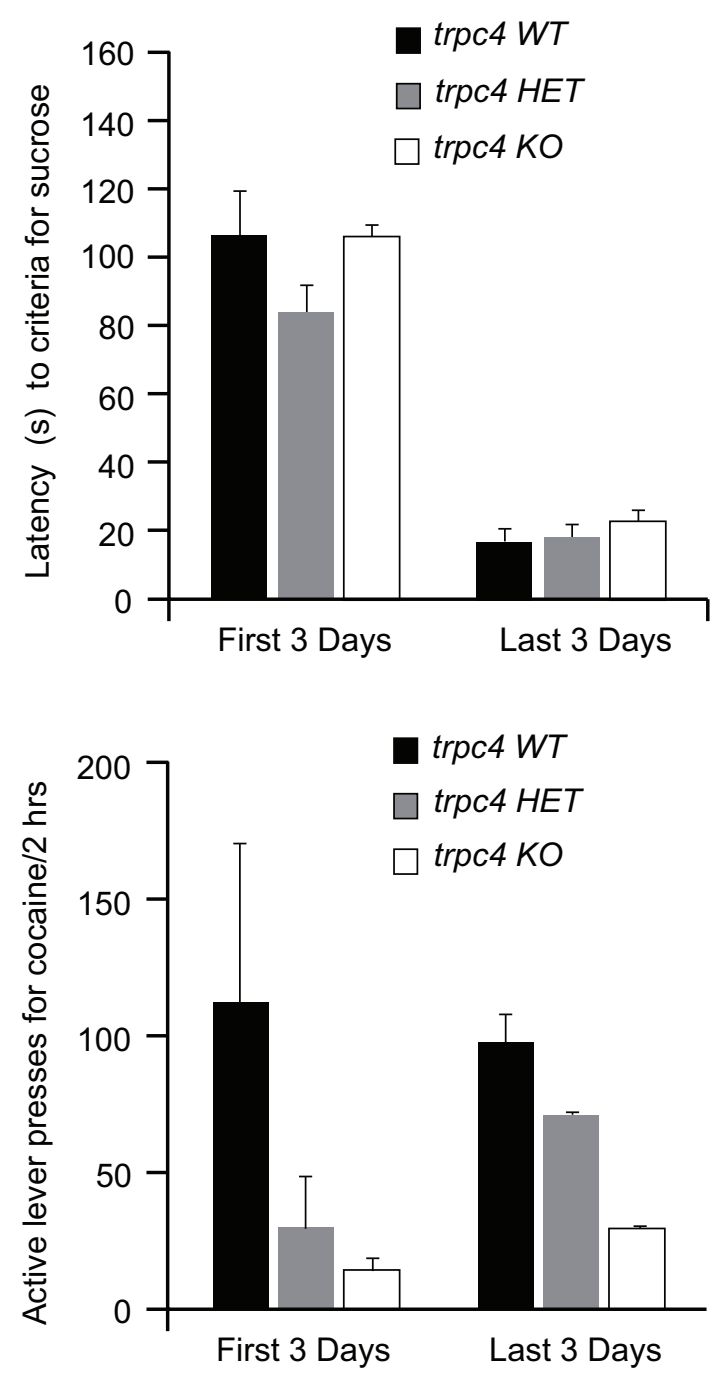

Figure 2. Sucrose and cocaine self-administration in the trpc4KO, WT and HET rats. A) The average latency in seconds for the trpc4 knock-out (KO), wild-type (WT) and heterozygote (HET) rats to acquire 50 sucrose pellets in the allotted time period (120 minutes) during the first 3 days and the last 3 days is shown. The animals learned to lever-press for sucrose pellets on a fixed-ratio 1 (FR1) reinforcement schedule for 5 days/week. All self-administration chambers were equipped with an active and inactive lever. The active lever was paired with a discriminative cue light stimulus. A correct lever response resulted in the sucrose reward, the termination of the cue light, and a 20 second time-out (TO 20s) period where responding produced no consequences. B) The average self-administered cocaine for WT, HET and KO rats during daily 2 hour sessions on a FR1 reinforcement schedule for the first 3 days and last 3 days of acquisition is shown.

\section{Cocaine self-administration}

We next sought to determine whether trpc4-KO rats would differ in cocaine reinforced behavior. Cocaine self-administration summary 
results are presented in the trpc4-KO, WT and trpc4 heterozygote (HET) rats on an FR1 schedule of reinforcement (Figure 2). Figure 2B illustrates a reduction in responding to cocaine in the $\operatorname{trpc4}-\mathrm{KO}$ group over the first 3 days and last 3 days (Figure 2B). The submitted data set contains responding on the active and inactive levers and the number of cocaine infusions for all three treatment groups across thirteen days of cocaine self-administration training.

\section{Summary}

Data is presented showing acquisition of sucrose and cocaine selfadministration infusions in trpc4 WT, HET and KO rats. The summary data show that for the first and last 3 days, rats lacking a functional trpc4 gene have normal sucrose mediated reward, and reduced acquisition of cocaine self-administration compared to WT rats.

\section{Sucrose and cocaine self-administration data set}

2 Data Files

http://dx.doi.org/10.6084/m9.figshare.642878

Raw data: Sucrose and cocaine self-administration data set This data set includes raw data for sucrose intake and cocaine self-administration experiments for all three rat strains used in our study - trpc4-KO, wild-type and heterozygous animals. The sucrose intake data is over a 10-day period, while the cocaine self-administration data is 13 days. Both data sets include averages for the first 3 days and last three days of experiments, also shown in Figure 2. Catheter patency tests and lever press data is also included. Catheter patency was tested and recorded daily. Lever press data shows the total lever presses (inactive and active) for each animal, which will differ from number of drug infusions due to the time-out period between infusions.

\section{Author contributions}

$\mathrm{KR}, \mathrm{RKB}$ and DCC designed the experiments, assembled and summarized the data and wrote the paper. CEO carried out the experiments.

\section{Competing interests}

No relevant competing interests were disclosed.

\section{Grant information}

This work was supported by National Institute on Drug Abuse (NIDA) grant R01 DA24040 (DCC).

The funders had no role in study design, data collection and analysis, decision to publish, or preparation of the manuscript.
1. Putney JW: Physiological mechanisms of TRPC activation. Pflugers Arch. 2005; 451(1): 29-34.

PubMed Abstract | Publisher Full Text

2. Schaefer M, Plant TD, Obukhov AG, et al:: Receptor-mediated regulation of the nonselective cation channels TRPC4 and TRPC5. J Biol Chem. 2000; 275(23): 17517-17526.

PubMed Abstract | Publisher Full Text

3. Zhu $\mathrm{X}$, Jiang $\mathrm{M}$, Peyton $\mathrm{M}$, et al.: trp, a novel mammalian gene family essential for agonist-activated capacitative Ca2+ entry. Cell. 1996; 85(5): 661-671. PubMed Abstract | Publisher Full Text

4. Clapham DE, Runnels LW, Strubing C: The TRP ion channel family. Nat Rev Neurosci. 2001; 2(6): 387-396. PubMed Abstract | Publisher Full Text

5. Ordaz B, Tang J, Xiao R, et al:: Calmodulin and calcium interplay in the modulation of TRPC5 channel activity. Identification of a novel C-terminal domain for calcium/calmodulin-mediated facilitation. J Biol Chem. 2005; 280(35): 30788-30796.

PubMed Abstract | Publisher Full Text

6. Fowler MA, Sidiropoulou K, Ozkan ED, et al.: Corticolimbic expression of TRPC4 and TRPC5 channels in the rodent brain. PLoS One. 2007; 2(6): e573.

PubMed Abstract | Publisher Full Text | Free Full Text

7. Geurts AM, Wilber A, Carlson CM, et al:: Conditional gene expression in the mouse using a Sleeping Beauty gene-trap transposon. BMC Biotechnol. 2006; 6: 30. PubMed Abstract | Publisher Full Text | Free Full Text

8. Klipec WD, Nguyen P, Deeney B, et al:: Deletion of the trpc4 gene and its role in simple and complex strategic learning. Nat Prec. 2012. Publisher Full Text

9. Rasmus KC, Wang JG, Varnell AL, et al.: Sociability is decreased following deletion of the trpc4 gene. Nat Prec. 2011

Publisher Full Text 


\section{Open Peer Review}

\section{Current Peer Review Status:}

\section{Version 1}

Reviewer Report 14 May 2013

https://doi.org/10.5256/f1000research.1161.r948

C 2013 Simpson E. This is an open access peer review report distributed under the terms of the Creative Commons Attribution License, which permits unrestricted use, distribution, and reproduction in any medium, provided the original work is properly cited.

\section{Eleanor Simpson}

Department of Psychiatry, Columbia University, New York State Psychiatric Institute, New York, NY, USA

This article addresses if loss of TRPC4 affects self administration of sucrose and cocaine. The title is appropriate and the abstract is a suitable summary of the article. The article is clearly written, the experiments are properly conducted and the methods are sufficiently described. The data file provided is clearly laid out, and most of the relevant data is included. It would be useful for the authors to also include lever press data for the sucrose self administration task, in case there is a strain difference in responding on the active lever during the 20 s timeout periods between trials.

Statistical analysis of both lever press data as well as \# cocaine infusions across sessions will determine if the authors claim that acquisition of cocaine self administration is reduced in TRPC4 KO rats is statistically significant.

Competing Interests: No competing interests were disclosed.

I confirm that I have read this submission and believe that I have an appropriate level of expertise to confirm that it is of an acceptable scientific standard.

Reviewer Report 10 May 2013

https://doi.org/10.5256/f1000research.1161.r904

(C) $2013 \mathrm{Hu}$ X. This is an open access peer review report distributed under the terms of the Creative Commons Attribution License, which permits unrestricted use, distribution, and reproduction in any medium, provided the original work is properly cited.

\section{Xiu-Ti Hu}


Department of Pharmacology, Rush University Medical Center, Chicago, IL, USA

The purpose of this study was to determine whether cocaine self-administration of rats was altered by trpc 4 knockout (KO). The title is appropriate and the Abstract is a suitable summary for this article. The article is well-constructed and clear. Outcomes from this study were important, suggesting a potential role of TRPC4 channels in neurons that mediate cocaine self-administration in the related structures of the rat brain. The study was well-designed and sensible data are obtained using a cutting-edge technology. Providing the methods and statistical results will further strengthen this article.

Competing Interests: No competing interests were disclosed.

I confirm that I have read this submission and believe that I have an appropriate level of expertise to confirm that it is of an acceptable scientific standard.

The benefits of publishing with F1000Research:

- Your article is published within days, with no editorial bias

- You can publish traditional articles, null/negative results, case reports, data notes and more

- The peer review process is transparent and collaborative

- Your article is indexed in PubMed after passing peer review

- Dedicated customer support at every stage

For pre-submission enquiries, contact research@f1000.com

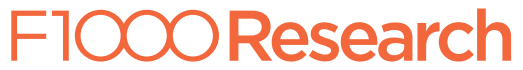

